\title{
ORALIDAD Y TRANSCULTURACIÓN \\ EN LA POESÍA DE RAMÓN PALOMARES
}

POR

\author{
Américo Arellano \\ Universidad Simón Bolivar
}

Casi todos los trabajos críticos sobre la obra poética de Ramón Palomares (1935) señalan —en forma explícita o no- la apropiación de elementos pertenecientes a la realidad cultural de los sectores rurales y campesinos de los Andes venezolanos, es decir, de aquella producción cultural que responde a una concepción del mundo claramente diferenciada respecto a las formaciones culturales de los sectores urbanos.

Sin embargo, esa crítica, generalmente descriptiva y contenidista, no llega a explicar los modos de apropiación tanto desde la perspectiva de los procedimientos artísticos como de las vinculaciones que el producto literario mantiene con la realidad cultural de la cual surge: qué tipo de elementos se toman, cómo funcionan en el discurso poético, qué modificaciones realizan o propician desde el punto de vista estético-ideológico. ${ }^{1}$

Para responder a estas interrogantes es conveniente revisar primero, aunque de manera breve, las relaciones entre la producción poética de Palomares y el sistema literario y cultural en el cual se insertan, porque nos ayudarán posteriormente a entender algunos de los problemas planteados.

Ramón Palomares pertenece a una generación de poetas marcados políticamente por la dictadura de Marcos Pérez Jiménez (1952-1958) en Venezuela y la Revolución Cubana (1959) en el ámbito latinoamericano.

El grupo Sardio, fundado en 1958 e integrado, entre otros, por Guillermo Sucre, Adriano González León, Luis García Morales y Francisco Pérez Perdomo, propicia una estética oscilante entre la tendencia surrealista - con marcadas influencias del grupo Viernes (1938-1941) - y la proyección de una realidad con fuertes contradicciones en el orden político social y económico. Los poetas "sardinistas" buscan incorporar esas manifestaciones de la realidad como toma de conciencia de la necesidad de renovar el sistema literario y de responder ideológicamente a la problemática socio-cultural venezolana.

\footnotetext{
${ }^{1}$ En rigor, el único trabajo que resuelve algunos de estos problemas es: Paul Borgeson, Jr., "Lo andino y lo universal en la poesía de Ramón Palomares" (University of Illinois, trabajo inédito).
} 
Es necesario elevar a perspectivas universales los alucinantes temas de nuestra tierra ... Nuestra cultura aparece ayuna de ideas y problemas como si aún viviéramos en una Arcadia de imperturbables regocijos. Hay que poner de relieve una conciencia más dramática de la realidad y el hombre. ${ }^{2}$

En este contexto, se publica $E l$ reino $(1958)^{3}$ - primer poemario de Ramón Palomares - en el cual funcionan simultáneamente algunos componentes surrealistas junto a otros vinculados en lo temático a una realidad cultural de carácter regional o del entorno personal que constantemente motiva al poeta.

La interacción - aparentemente contradictoria - de esas diversas formas de producción poética pone de relieve en el nivel estético-ideológico la problematización de una fase transitoria en el sistema literario y reclama un cambio de códigos que sean capaces de responder de manera más adecuada por la realidad inmediata del país, afectada por la desestabilización política y social a consecuencia de la dictadura perezjimenista y la incertidumbre del incipiente sistema democrático.

Agustín Cueva señala que el quehacer literario en los diversos períodos de la historia literaria se encuentra determinado por la infraestructura económico-social, la cual va a constituir una "matriz histórico-estructural" sobre la que han de desenvolverse las "prácticas que denominamos literarias". ${ }^{4}$ En Venezuela, las circunstancias políticas y las relaciones económico-sociales adquieren un matiz fuertemente contradictorio que va a reflejar el inconformismo de los diversos sectores del conglomerado social en expresiones como la violencia de los años sesenta y en la actitud desmitificadora de la realidad cultural en los artistas y poetas de ese período.

Un ejemplo de este reclamo, es el trabajo de grupos como Techo de la Ballena (1961) y Tabla Redonda (1962) quienes propiciarán una poesía (y un arte) de índole subversiva, violenta, de rebelión contra las normas establecidas (el culto a la necrofilia, por ejemplo, en Techo de la Ballena).

Sin embargo, en la evolución de la obra poética de Palomares y la de otros poetas de la misma generación, podemos observar que la comprensión de la realidad y su expresión artística, aunque no deja de estar vinculada por una cierta rebeldía contra el entorno socio-cultural, tomará diferentes vías temáticas y expresivas, y será más bien el "fondo generacional"'s lo que los unirá históricamente. ${ }^{6}$

Por su parte, Palomares dirigirá su trabajo hacia la proposición de una poética que reivindique las manifestaciones de la cultura rural y campesina de los Andes en sus

\footnotetext{
2 "Testimonio", Sardio. Revista Bimestral de Cultura (mayo-junio 1958) 1.

${ }^{3}$ Este libro fue publicado por el grupo Sardio.

${ }^{4}$ Agustín Cueva, "El método materialista histórico aplicado a la periodización de la historia de la literatura ecuatoriana: algunas consideraciones teóricas", Casa de las Américas 127 (La Habana, 1981) 31-36.

${ }^{5}$ Paul Borgeson, "Lo andino y lo universal en la poesía de Ramón Palomares" 1.

${ }^{6}$ Sobre la evolución de los poetas de la década del sesenta es interesante el trabajo de Javier Lasarte Valcárcel, "Posible resplandor que apenas es. (La poesía de la promoción del 60 en esta década)", en el cual señala los cambios sufridos por ellos y su incidencia en la actividad literaria y cultural realizada posteriormente. Imagen 100-23 (Caracas, octubre de 1986) 20-22.
} 
componentes temáticos, lingüísticos y de concepción del mundo, proponiendo de este modo un proyecto estético nuevo en el sistema literario venezolano, que de alguna manera es la respuesta literaria a un proyecto de cambio social. ${ }^{7}$

Posteriormente, poetas más recientes como Luis Alberto Crespo, Ramón Querales, José Berroeta, Blas Perozo Naveda, y Enrique Hernández D’Jesús ${ }^{8}$ producen un tipo de poesía con propuestas más o menos similares. El primero de ellos, por ejemplo, incorpora la realidad cultural de la región caroreña, fundamentalmente en lo temático.

Otros poemarios de Palomares - Honras fúnebres (1966), Santiago de León de Caracas (1967), Elegía 1830 (1980)- exploran un discurso poético (por ejemplo, ciertas expresiones arcaicas o voces indígenas en Santiago León de Caracas) que confronta a la visión de la historia como manifestación exclusiva de un sector socialmente dominante, la versión no oficial de aquellos grupos que han sido exterminados o reducidos en sus prácticas socio-culturales.

Ahora bien, debido a que el objeto de nuestra investigación consiste en revisar las formas de apropiación (y su funcionamiento) de aquellos elementos pertenecientes al entorno cultural popular, en este caso el rural y campesino de los Andes venezolanos, limitaremos el corpus de trabajo a El reino (1958), Paisano (1964) y Adiós Escuque $(1974)^{9}$ porque es en ellos donde se verifica con mayor amplitud y significación dicha apropiación, sobre todo en los dos últimos.

De antemano queremos observar que la incorporación de las fuentes populares no se corresponde con los esquemas del regionalismo tradicional, inserto dentro de un modelo descriptivo de la cultura popular, sino con las propuestas renovadoras posteriores al regionalismo que buscan restaurar en forma dinámica y con proyección universal los elementos característicos de estas culturas desde sus posibilidades expresivas y de concepción del mundo, en lo que Ángel Rama denomina literatura de la "transculturación", ${ }^{10}$ aquélla con una clara intención reivindicativa, ${ }^{11}$ que le permite formular un proyecto estético que pone de relieve las manifestaciones culturales de las regiones internas y no como simples receptoras de modelos foráneos.

${ }^{7}$ El mismo Palomares dice en entrevista con Miriam Marinoni: "Siempre quise plantear la reivindicación del mundo regional desde la defensa de su proyección como algo universal". Miriam Marinoni, "El telurismo mítico en la poesía de Ramón Palomares". (Tesis de Maestría. Caracas: Universidad Simón Bolívar, 1984) 178.

${ }^{8}$ De ellos, quien ha logrado una obra más consistente desde la perspectiva de la oralidad popular es Luis Alberto Crespo, sobre todo en Costumbre de sequia (1976). Véase Naudy Enrique Lucena, "Ramón Palomares y Luis Alberto Crespo: poética de regionalidad trascendida". (Tesis de Maestría. Caracas: Universidad Simón Bolívar, 1985).

${ }_{9}$ Para el presente trabajo utilizamos la edición Ramón Palomares, Poesía 1958-1965 (Caracas: Instituto Pedagógico, 1973). Esta edición, con prólogo de Iraset Páez Urdaneta, contiene los libros El reino (1958), Paisano (1961-1962) y Honras fúnebres (1965). Y, Adiós Escuque (Mérida: Ediciones de la Universidad de los Andes, Colección Actual, 1974)

${ }^{10}$ Ángel Rama, Transculturación narrativa en América Latina (México: Siglo XXI Editores, 1982).

"Sobre los modelos descriptivo y reivindicativo de la cultura popular véase Yolanda Salas de Lecuna y otros, "Problematización de la cultura popular: modelos de análisis y su aplicación a textos caribeños", Tilalc 3 (Caracas: Universidad Simón Bolívar, 1986) 5-16. 
Un universo cultural es complejo, dinámico y contradictorio, es una estructura conformada por la articulación de elementos disímiles que pueden ser vistos como pequeñas unidades integradas al todo cultural. En la obra literaria, por lo general, se asume de ese modo, la construcción del referente literario a partir de dicha realidad. Palomares integra en el texto poético lo individual (personal) y lo colectivo; lo cotidiano y lo trascendente; lo regional y lo universal; lo tradicional y lo innovador (o extranjerizante); lo racional y lo mítico; la oralidad y la escritura. Articula aquellos elementos que pertenecen a realidades culturales distintas pero que funcionan dialécticamente y se integran a una visión del mundo asumida desde una perspectiva reivindicadora del sector cultural tradicionalmente soslayado.

Para facilitar el análisis de acuerdo a los requerimientos del presente trabajo, clasificaremos en dos tipos los elementos culturales populares que serán estudiados: los motivos temáticos y la oralidad como estructura literaria y concepción del mundo.

\section{NúCLEOS TEMÁTICOS}

Las manifestaciones de tipo temático presentes en la poesía de Palomares son muy variadas, pero tienen en común una singular motivación personal cuyo origen está en la visión nostálgica del pasado rural y campesino opuesto al presente urbano, es decir, el asombro infantil ante una naturaleza deslumbradoramente mágica y la conciencia desmitificadora de una realidad contradictoria en el orden social y cultural, percibidas por el poeta -intermediario entre ambos espacios culturales — con una visión nostálgica por la pérdida del origen.

La naturaleza integradora, ${ }^{12}$ entendida como relación dinámica entre el hombre y lo natural (montañas, ríos, niebla, el sol, los animales, etc.), es el motivo que pone en funcionamiento la memoria que reactualiza las tradiciones, las fiestas religiosas y el sistema de creencias de los sectores campesinos de la región andina.

$\mathrm{Al}$ respecto, el mismo poeta dice:

... recuerdo con especial intensidad y afecto las imágenes de las montañas de mi infancia desde donde surgían reflejos que eran además de fulgor gentes, reales y fantasmales, del momento o de un remoto pasado, y que se internaban en mi imaginación abriéndose caminos hacia aldeas y formaciones de nubes perdidas e imposibles ... algunos caminos en regiones abruptas (picos y cordilleras que cerraban el horizonte misteriosamente velados de niebla persistente), presionaban casi dolorosamente mi espíritu llenándome de voces y fábulas, voces y fábulas que luchaban por ascender de lo más profundo de mi pasado de niño solitario, niño encaramado en un árbol amigo contemplando difuminados caballos, unos pájaros, la distancia de cielos recargados, amorosos es cierto, pero también sombríos. ${ }^{13}$

\footnotetext{
${ }^{12}$ Preferimos hablar de naturaleza integradora y no de paisaje, porque este término está más asociado literariamente con un tipo de literatura "regionalista", "criollista", "provinciana" que no responde al sentido renovador de la poesía de Palomares.

${ }^{13}$ Ramón Palomares, "Poesía y lenguaje", "Papel Literario" de El Nacional (Caracas, 31 de mayo, 1987) 3.
} 
Lo extenso de la cita destaca la importancia de la naturaleza en la poesía del poeta trujillano como elemento generador de la creación poética desde una perspectiva totalizadora del referente cultural, frente a un tipo de literatura que la asume en sus posibilidades paisajísticas, creando una distancia entre la realidad y su expresión poética al modo de lo meramente descriptivo.

En Palomares, el motivo de la naturaleza asume dos modos de representación.

En el primero, es una voz infantil que reproduce el asombro frente a un orden natural entendido como revelación mágica mediante una actitud y un pensamiento no lógicoracional, sino totalizador e integrado. Este modo de representación es utilizado en todos los textos de "Juegos de infancia", el primer apartado de Paisano. Veamos, como ejemplo, parte del poema "El Sol":

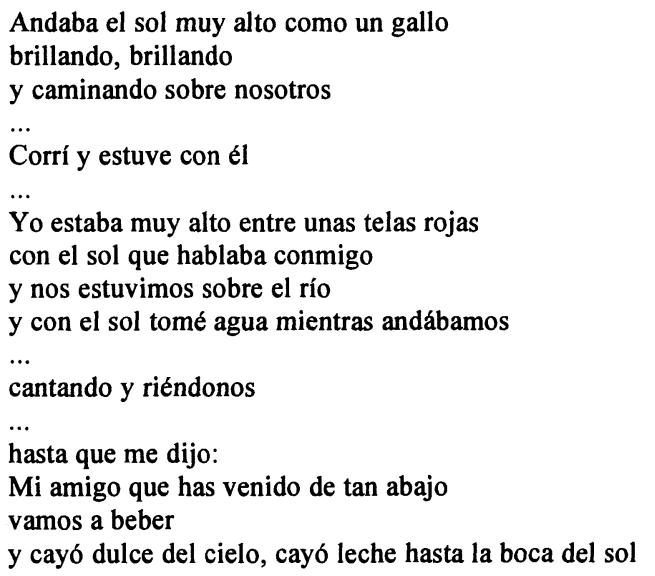

(“El sol”, Paisano 118)

La relación hombre-naturaleza, portadora de un efecto lúdico y encantatorio, traduce, en el ejemplo citado, un tipo de conciencia que se caracteriza por el asombro y la visión mágica - como suele ser la del niño- con que se contemplan las distintas manifestaciones del mundo natural. Encuentro en el cual sólo es posible el deslumbramiento, la inocencia interrogadora que procura responderse por la vía de la identificación positiva a los misterios que la naturaleza le plantea.

El segundo modo de representación es a través de una naturaleza personalizada, animada, que se transforma en hablante para expresarse sobre sus propios fenómenos con un sentido diferente al que vimos en "Juegos de infancia". Está presente, sobre todo, en "Tierra de nubes" - el segundo apartado de Paisano - (también es posible encontrarlo con menos incidencia y referido por otro hablante lírico en un texto como "Despedida de Laurencio", de Adiós Escuque). En aquel poemario, los fenómenos naturales (el viento, la lluvia, el trueno, etc.) dejan de tener la función de deslumbramiento que vimos en "Juegos de infancia" para impregnarse de un sentido agonístico respecto a la realidad: la naturaleza agresora que contribuye a desmejorar la desvalida situación social del hombre campesino. 


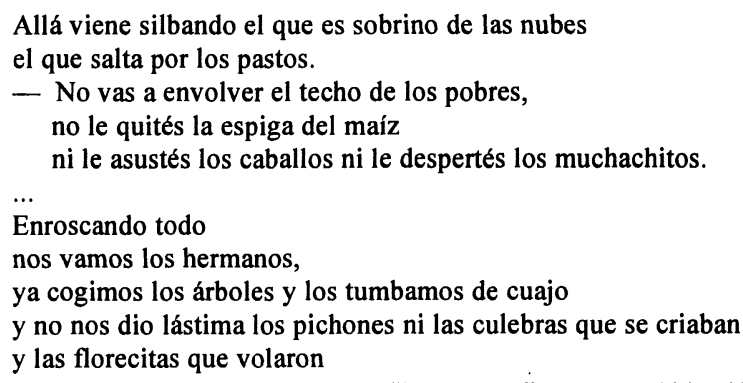

(“Hermanos", Paisano 139-140)

Decíamos anteriormente que del reencuentro con la naturaleza surgían otros núcleos temáticos presentes en Paisano y Adiós Escuque. En efecto, las tradiciones, las fiestas religiosas, el sistema de creencias del sector cultural campesino de los Andes se reactualizan al ser convertidos en motivos de creación poética, funcionando como exponentes de un sistema cultural regional que proyecta una concepción del mundo distinta a la de los sectores metropolitanos y de la dominación, pero también legítimamente poseedores de universalidad.

El tratamiento etnográfico con que cierta crítica $^{14}$ suele abordar el estudio de la poesía de Palomares sólo permite observar en la reproducción poética de hechos y creencias de la cultura popular andina un mero registro de elementos pertenecientes a un entorno cotidiano de simple interés folklórico. Las limitaciones de este tipo de crítica, en las cuales suele esconderse veladas intenciones ideológicas de los sectores culturales de la dominación, impide la producción de un conocimiento comprensivo de las verdaderas posibilidades significativas de dichos elementos que, en el caso de Palomares, van mucho más allá de querer ser el simple registro de una determinada realidad.

El modo como el poeta trujillano aborda la reproducción de esos elementos es distinto al del poeta o narrador que desde su posición de "intelectual ilustrado", omnipotente productor de materiales artísticos, va hacia la realidad cultural de los sectores culturales tradicionalmente silenciados, para ejercer una apropiación que generalmente permite mostrar a la cultura "ilustrada" la existencia de otras manifestaciones culturales que reafirman su particular concepción de lo nacional para legitimar falsamente la diversidad cultural que no registra los conflictos y las transformaciones operadas en uno y otro sector.

Por el contrario, en Paisano y Adiós Escuque, a partir de experiencias personales y familiares, el poeta se interna en la cotidianidad del mundo campesino para registrarlo como experiencia colectiva, portadora de un pensamiento y una concepción del mundo con características propias que subyacen como entidades legítimas de una expresión cultural distinta a aquélla que se ha oficializado en los centros metropolitanos de poder.

\footnotetext{
${ }^{14}$ Para Juan Liscano, por ejemplo, Palomares es "un primitivo, un espontáneo de la fe revolucionadora" y en su poesía su "orientación creativa [está] próxima a lo que más parecía aborrecer la generación sardista: el folklore", Panorama de la literatura venezolana actual (Caracas: Publicaciones Españolas, S.A., 1973) 283. Véase Ramón Palomares, "Poesía y lenguaje".
} 
Entendida de esta manera, la discursividad poética en los poemarios citados es directamente inversa a la señalada por María Elena Maggi en su libro La poesía de Ramón Palomares y la imaginación americana, según la cual en Adiós Escuque la poesía del autor trujillano "sufre una reducción: de los grandes mitos, de lo colectivo, el poeta pasa a tratar lo autobiográfico, lo individual, ahora evoca su infancia y sus primeras experiencias y recuerdos". ${ }^{15}$ Es cierto que en este poemario - también en Paisano y en algunos textos de El reino- la materia de la cual surge la producción poética está impregnada —como dijimos antes - de las experiencias personales y familiares del poeta. No obstante, ello sólo ocurre en el nivel del enunciado, porque el sentido que nos transmiten los textos supera esa individualidad ${ }^{16}$ y alcanza la expresión de la conflictividad socio-cultural de todo un sector que tiene en el poeta a un intermediario que los comunica con aquel otro que practica el soslayamiento.

Por supuesto que estos elementos temáticos no bastan para determinar el grado de despojamiento de lo individual y la proyección de un universo colectivo en ambos poemarios. Habría que revisar un aspecto fundamental como es la oralidad, a partir de la cual se elabora el discurso poético. Pero nos detendremos antes con algunos ejemplos donde se pueda observar mejor lo dicho hasta ahora.

Dentro del sistema de tradiciones y creencias de la cultura popular andina el aspecto religioso posee características muy particulares, cuyas raíces están no sólo en la tradición cristiana, sino también en las culturas precolombinas. ${ }^{17}$

Lo religioso en Paisano y Adiós Escuque se manifiesta a través de dos vertientes fundamentales: la evocación de fiestas y tradiciones religiosas, como las festividades navideñas y la enseñanza de la fe cristiana ("Diciembre andando por el cielo" y "Las Catequistas" de Adiós Escuque $)^{18}$ y la particular concepción de la muerte como una presencia fantasmal en el mundo de los vivos en varios poemas de Paisano y Adiós Escuque.

"Diciembre andando por el cielo" evoca una costumbre muy propia de la tradición cultural andina venezolana: el robo del niño Jesús y su posterior búsqueda colectiva por el vecindario en una fiesta donde generalmente participa todo el pueblo:

\author{
"Que al Niño Jesús Perdido \\ lo venimos a buscar ..." seguíamos \\ “¡Pobre Virgen María!” — decía la gente \\ Los Reyes Magos bien rascados \\ caracoleando los caballos ...
}

\footnotetext{
${ }^{15}$ María Elena Maggi, La poesía de Ramón Palomares y la imaginación americana (Caracas: Centro de Estudios Latinoamericanos Rómulo Gallegos, 1982) 39. Por el contrario, el último poema de Adiós Escuque - "Adiós"- es la representación poética del mito cosmogónico de la creación.

${ }^{16}$ Inclusive, un texto tan personal como "Despedida de Laurencio" adquiere un sentido muy colectivo por la manera como es redimensionada la experiencia de la muerte.

17 En "Palomares. Conversación en París". Entrevista con Amado Durán, Zona Franca, 35-36 (Caracas, mayo-septiembre 1983) 32.

${ }^{18}$ También hay poemas que recrean temas bíblicos como el hijo pródigo y la expulsión del paraíso terrenal ("El hijo pródigo" y "La caída", de Adiós Escuque).
} 


\author{
" ¡Cuidado con esas bestias!" \\ Velas y faroles incendiaban las calles \\ los músicos reventaban sus cuerdas $\mathrm{Y}$ el cielo \\ arrebataban las pastorcitas
}

("Diciembre andando por el cielo", Adiós Escuque 13)

El diálogo con la tradición se renueva desde la perspectiva de lo popular por la multiplicación de las voces que van refiriendo la situación anecdótica (identificadas en el texto por las comilla), distintas a la del hablante lírico que construye el poemario. Es decir que dichas voces surgen de su propia situación enunciativa como expresión de una determinada manifestación cultural.

La muerte, presente desde El reino, tiene menos que ver con el pensamiento occidental, porque se concibe como una presencia fantasmal en el mundo de los vivos. Son ánimas en pena, aparecidos que deambulan y entablan conversación con los vivos:

Sos el ánima de Ismael, sos la rueda de candela sos la mujer de las tres gallinas sobre los hombros

Ánima de Ismael decí dónde están los cobritos, dónde pusistes la busaca, dónde metites los cobres ánima de Ismael.

...

Te vimos llegar y te sentate en el patio $y$ te quejabas.

Vos que sos un ánima Ismael, vos que nadás por las tinieblas, te escuchamos

(“Ismael", Paisano 137-138)

Eramos árboles y gentes del sueño almas erradas Errantes árboles y furiosos dábamos vueltas a la vida Hurgando unas cenizas Hurgando unos rescoldos más allá de nosotros

(“Abuelos muertos, tías, retías y demás sombras", Adiós Escuque 59)

Si bien esta caracterización de la muerte es común en varias culturas donde subyace un pensamiento mítico, lo particular a la tradición andina venezolana está dado fundamentalmente en el nivel discursivo mediante el uso dialectal del lenguaje oral campesino, tal como puede observarse en el primero de los ejemplos citados antes.

Por otra parte, en todos los poemarios prevalece la idea de la muerte como "una gran soledad", ${ }^{19}$ que ha sido trabajada también de esa manera por escritores como Rulfo y García Márquez.

\footnotetext{
${ }^{19}$ Ramón Palomares, en la entrevista con Amado Durán.
} 


\section{LA ORALIDAD POPULAR: PRINCIPIO COMPOSITIVO Y PERSPECTIVA DE ENUNCIACIÓN}

La recuperación de los elementos temáticos no hubiese tenido un impacto renovador si sobre ellos el poeta no ejerce un modo de representación distinto al tradicionalmente utilizado por la literatura regionalista y criollista. Para su reelaboración artística, Palomares asumió los medios de expresión y de concepción del mundo de la realidad cultural representada como elementos estructurantes del conjunto poético y no como simples recursos de un trasunto literario.

La oralidad es, en ese sentido, el indicador del fenómeno cultural popular que estructura la producción literaria y opera las transformaciones estético-ideológicas. Como tal, debemos entender que la oralidad es un tipo de fenómeno que abarca tanto a la configuración lingüística como al sistema de pensamiento y de visión del mundo de aquellas comunidades que culturalmente funcionan con mecanismos distintos a los que rigen a los sectores culturales comprendidos por la escritura. Pero su reelaboración artística tampoco es una mera reproducción del fenómeno cultural, sino que el poeta (o el narrador) debe adaptar a las particularidades de la escritura (y en este caso del discurso poético) los principios que la ordenan en la realidad cultural. La oralidad como estructura artística es, por lo tanto, una recreación del fenómeno oral popular.

Siguiendo a Ángel Rama en su libro Transculturación narrativa en América Latina, ${ }^{20}$ revisaremos de qué manera funciona la oralidad como estructura artística en la poesía de Palomares, primero en su conformación lingüística y su estructuración literaria y, luego, las transformaciones que propugna a nivel estético-ideológico.

\section{El componente lingüistico}

Algunos poemas de El reino ("Elegía a la muerte de mi padre", "Conquistas") muestran ya el deseo de querer reproducir el efecto del fenómeno oral en el discurso poético. En el primero de los poemas citados, el poeta trata de recrear las posibilidades dialógicas del lenguaje oral con la elaboración de un discurso donde parece conversar consigo mismo sobre la muerte del padre, utilizando el tono imperativo en el otro con quien supuestamente dialoga:

Esto dijéronme:

Tu padre ha muerto, más nunca habrás de verlo.

Abrele los ojos por última vez.

Con la terrible mano tuya recórrelo

y huélelo como siguiendo el rastro de su muerte

y entreábrele los ojos por si pudieras

mirar a donde ahora se encuentra

("Elegía a la muerte de mi padre", El reino 47)

\footnotetext{
${ }^{20}$ Ángel Rama, Transculturación narrativa en América Latina.
} 
El tono empleado aquí es similar al utilizado por Juan Rulfo ${ }^{21}$ —scritor que también reproduce en su obra literaria las particularidades del lenguaje oral- en el cuento "En la madrugada" en la voz de uno de los personajes, aunque, obviamente, las circunstancias son diferentes:

(El viejo Esteban) dejó al último, a la desahijada [la vaca] que se estuvo brame y brame, hasta que por pura lástima la dejó entrar. "Por última vez -le dijo; míralo y leng Ÿetéalo; míralo como si fueras a morir ...". Y a él: Saboréalas nomás, que ya no son tuyos. ${ }^{22}$

Lo similar de la estructura lingüística en los ejemplos anteriores sirve para demostrar que ésta subyace en el fenómeno oral de América Latina como parte de un sistema lingüístico que posee rasgos comunes dentro de las múltiples diferencias que lo caracterizan en los distintos espacios geográficos.

En Paisano y Adiós Escuque, el discurso recurre más a las manifestaciones dialectológicas del lenguaje oral del sector rural andino, aquel que el mismo poeta define como "la palabra de uso y comprensión locales". ${ }^{23}$ Como bien lo señala Ángel Rama, en el tipo de literatura que se plantea en los términos de la transculturación:

el autor se ha integrado a la comunidad lingúística y habla desde ella ... Si esa comunidad es, como ocurre frecuentemente, de tipo rural, o aun colinda con una de tipo indígena, es a partir de sus sistema linguístico que trabaja el escritor, quien no procura imitar desde fuera un habla regional, sino elaborarla desde dentro con una finalidad artística. ${ }^{24}$

Cuando el texto artístico se construye de esta manera, las transformaciones operadas en el discurso poético inciden no tanto en el sistema lingüístico de la lengua oral como en los principios mismos de la escritura y de la estructuración literaria, que deben adaptarse a los mecanismos expresivos de la oralidad. Por ejemplo, la sintaxis, en la escritura, rompe con la normativa académica y se reproduce al modo mismo del lenguaje oral, o la estructura narrativa no se elabora con los recursos expresivos impuestos por la tradición literaria, sino más bien con el "discurrir dispersivo" 25 de la narración oral. Lo que Arguedas llama "lengua artificial" - aquélla creada por él a partir de las modulaciones y la sintaxis del quechua - no es otra que un tipo de lenguaje que ha modificado los elementos propios de la escritura y de un idioma que pretende ser lógico en su expresión escrita (el español) desde otro que es fundamentalmente de construcción oral (el quechua).

En la poesía de Ramón Palomares - sobre todo en Adiós Escuque- las particularidades lingüísticas (el voseo, ciertos términos propios del habla regional

\footnotetext{
${ }^{21} \mathrm{El}$ autor mexicano es una de las influencias reconocidas por Palomares, aunque dice no haberlo leído todavía cuando escribió Paisano. Véase la entrevista con Amado Durán, 33.

22 Juan Rulfo, "En la madrugada", El llano en llamas. Obra Completa, T. 13 (Caracas: Biblioteca Ayacucho, 1977) 30.

${ }^{23}$ Ramón Palomares, "Poesía y lenguaje" 3.

${ }^{24}$ Ángel Rama 43.

${ }^{25}$ Ángel Rama 44.
} 
andina) ${ }^{26}$ el carácter narrativo de los poemas, la multiplicidad de voces que muchas veces subordinan al yo poético, componen la estructura artística del texto subvirtiendo los modos estatuidos del quehacer poético. Transcribiremos un poema completo de Adiós Escuque donde se pueden observar todos estos aspectos.

Dice que ya no le hacen falta flores que paqué

Que se las guarden pa la fosa - dice

- Yo no

A mí no

Por eso está cortando todo

No deja nada con cabeza

Por allí por allá

Los almendrones se pusieron blancos cuando pring!

comenzó a darles encaramado en la escalera

El

- A las gallinas

que vive envenenado

Al perro

A las matas de rosa

A todo A todo lo voy a fregar - dice

- Paqué flores

Paqué tanto animal

Pa puro echar jaretas!

Y Pring

Suena el machete en la ramita

Corta el fino y en el tronco

- Que se friegue todo

Que se fuña

Y ya en la casa no es más que afanar

$Y$ corta que te corta

Y "Tumbemeeso!"

Y “¡Bajemeeso!”

"Qué caray"

("Dice que ya no le hacen falta flores", Adiós Escuque 20-21)

El componente lingüístico del habla regional con el cual se elabora el discurso poético tiene sus raíces culturales, según Palomares, "en las sonoridades castizas del idioma español" y en "un habla impregnada del sonido distante de reminicencia indígenas (precolombina y timotocuica)", y "aunque este último haya desaparecido en tanto que estructura idomática lo cierto es que sus modulaciones y vocablos ciñen con asidua frecuencia nuestro lenguaje". ${ }^{27}$

\footnotetext{
${ }^{26}$ Véase María Elena Maggi, La poesía de Ramón Palomares y la imaginación americana. Miriam Marinoni, "El telurismo mítico en la poesía de Ramón Palomares". Naudy Enrique Lucena, "Ramón Palomares y Luis Alberto Crespo".

${ }^{27}$ Ramón Palomares, "Poesía y lenguaje" 3.
} 
Esa doble vertiente permanece en la realidad cultural como un tipo de habla que define a una comunidad lingüística y culturalmente. La función del poeta es entonces la del intermediario que se sirve de los mecanismos de la escritura para producir textos artísticos a partir de los componentes del lenguaje oral y popular de aquella comunidad.

\section{La voz colectiva: conciencia del universo oral popular}

Otras de las características que define la poesía de Palomares en cuanto estructura literaria que recupera las fuentes de la oralidad es la presencia constante de una voz colectiva desde la cual se elabora la situación enunciativa del poema. El hablante lírico se despoja de su individualidad y asume la voz que recrimina la inveterada agresión de la realidad, que mantiene vigente la historia local y reactualiza el pasado, proyectándolos, en virtud de su funcionamiento oral, sobre el sector dominado por la escritura para romper su silenciamiento como legítima concepción del mundo.

Paul Borgeson dice que:

los hablantes cambian vertiginosamente, se entremezclan en su diálogo espectral, y el que solemos llamar yo poético se subordina en grado notable, ofuscándose entre las múltiples voces - a veces de muertos-que pronuncian los versos. ${ }^{28}$

Nacimos en ese pueblo donde la gente vive preguntando por los de lejos

Y cuando caminábamos siempre íbamos por ese pueblo ...

Nosotros pasamos preguntando por una tierra

("Nativos", Adiós Escuque 53)

Eramos árboles y gentes del sueño

Almas erradas Errantes árboles

y furiosos dábamos vueltas a la vida

Hurgando unas cenizas

Hurgando unos rescoldos

más allá de nosotros

(“Abuelos muertos, tías, retías y demás sombras”, Adiós Escuque 59) Paisano.

Otros ejemplos característicos son "Juan León", "Huyendo", "Ismael”, "Reseco" de

Esta manera de estructurar el poema permite que la perspectiva de enunciación surja desde el universo representado y la concepción del mundo no sea la del poeta como mera individualidad sino la del sector comunitario, que es simultáneamente objeto de la creación poética y voz de su propio acontecer.

\footnotetext{
${ }^{28}$ Paul Borgeson 4.
} 
No obstante, la importancia de ambos niveles de la operación literaria —el lenguaje oral y la multiplicidad de voces- no anulan la función del poeta, porque éste se convierte en el intermediario entre el universo oral y aquel caracterizado por el dominio de la escritura. Ideológicamente, el poeta plantea las contradicciones de los contactos culturales, es el portador del cuestionamiento que la cultura silenciada ejerce sobre los secotres de poder.

\section{Oralidad y transculturación: un proyecto de transformación estética (y social)}

Sin ser tan evidente en una primera lectura, la representación literaria del fenómeno oral popular en la obra poética de Palomares muestra la oposición de sistemas culturales cuyos modos de producción cultural y visiones del mundo, si bien no son radicalmente distintos, en efecto poseen rasgos diferenciadores que de alguna manera dificultan el proceso de comunicación intercultural.

La obra poética es el producto artístico de la relación entre el sector rural y campesino de los Andes, ordenado en gran medida bajo los principios del pensamiento mítico y de la oralidad y los sectores urbanos de la dominación, regidos por la racionalidad y la escritura. De este modo, puede afirmarse que, en principio, dicha obra refleja una relación de heterogeneidad ${ }^{29}$ parcial, porque el referente popular no es culturalmente puro (en el sentido de que no haya sufrido influencias, culturales externas, por ejemplo, no es totalmente indígena), sino que está impregnado de rasgos de la cultura occidental, en su vertiente española. La problemática planteada mediante la literaturizacion de aquel referente responde más bien a un proceso continuo de desculturación a que está sometido el sector rural y campesino, el cual observa cómo va perdiendo progresivamente su tradición cultural ante el avance inminente y el silenciamiento que sobre él practican los sectores urbanos de la dominación.

Para el último grupo, los modos de producción cultural están directamente relacionados con los diferentes circuitos de difusión del producto artístico; asimismo, establecen en la totalidad del espacio cultural, los términos bajo los cuales han de desenvolverse los juicios valorativos sobre la obra de arte, que, según esta percepción es tal en cuanto que participa de los rasgos que invariablemente ha privilegiado la estética occidental. Para este punto de vista, la producción cultural popular adquiere un valor relativo: es un producto folklórico que contribuye a afirmar la concepción de lo nacional a través de la falsa permeabilidad de las distintas manifestaciones culturales.

Por el contrario, la producción cultural de los sectores dominados adquiere un valor y un sentido distintos, activos y legítimos, cuando se asume como manifestación de un conglomerado social cuya fisonomía cultural refleja un modo de ser diferente, con validez universal, aunque inserto en una realidad regional.

La cultura rural y campesina - por medio del poema como producto literarioenfrenta la creciente desculturación con la representación del fenómeno popular desde

${ }^{29}$ Para el concepto de heterogeneidad aplicado a la literatura véase el libro de Antonio CornejoPolar, Sobre literatura y crítica latinoamericanas (Caracas: Universidad Central de Venezuela, 1982). 
una postura reivindicativa, es decir, a través de una concepción transculturadora que "equilibre" la participación de los distintos sistemas en el proceso cultural.

En este ámbito de relaciones, la figura del poeta asume - como lo hemos venido afirmando - la función de intermediario de los contactos culturales entre ambos sectores. Este intermediario es un tipo de sujeto que trabaja sobre los medios de producción cultural del sector dominante (la escritura, el discurso que llamamos poético, el libro) para adecuarlos a los requerimientos expresivos —estética e ideólogicamente- del fenómeno cultural popular. Su intervención está mediatizada por la motivación personal que proyecta sobre el universo poético representado y que incide ambiguamente en la perspectiva de enunciación por cuanto refleja cierto pesimismo respecto a las posibilidades de transformación que se buscan con el proyecto transculturador. En efecto, tanto en Paisano como en Adiós Escuque hay un tono de nostalgia por el origen perdido, de angustia frente a un mundo que se percibe en permanente destrucción, incluso por los efectos mismos de la penetración foránea:

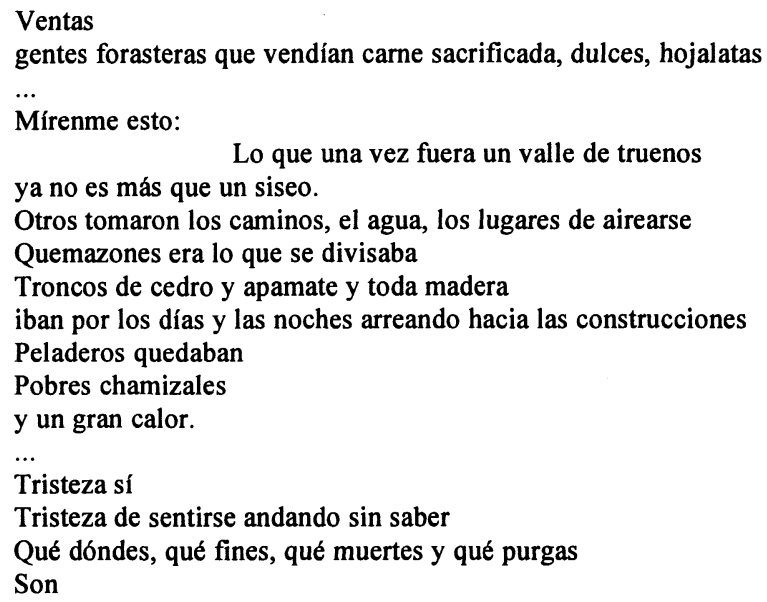

("Nativos", Adiós Escuque, 54)

No obstante, la participación del intermediario está sólidamente comprometida con las prácticas culturales de la comunidad campesina. Mediante la enajenación de los recuerdos de la escritura penetran los valores culturales establecidos para cuestionarlos con la existencia de este otro universo cultural como una clara respuesta a un tipo de literatura que enfrenta la producción artística de los sectores bajo dominación como simples manifestaciones de interés etnográfico, pero carentes de validez estética. En este tipo de literatura, la oralidad sólo es un recurso de imitación de las formas lingüísticas del habla popular. En cambio, en Paisano y Adiós Escuque, para el poeta como intermediario, el cual enfrenta el fenómeno oral desde lo interior, constituye la matriz que genera además toda una forma de pensamiento y de concepción del mundo, opuesta - en este caso, parcialmente dado que la heterogeneidad existente también es parcial- 
a otro sistema de pensamiento, determinado por la escritura, por su carácter urbano y de hegemonía cultural.

Debido a que el discurso poético sobre el cual trabaja el intermediario pertenece al universo escritural, la adaptación de los recursos de la oralidad está en parte mediatizada por los requerimientos del fenómeno escriturario, es decir que el texto poético es la ficcionalización de la oralidad popular y no ésta en sentido absoluto. Sin embargo, este problema queda salvado - y de ahí las diferencias con respecto a los escritores criollistas y del regionalismo tradicional, quienes procedieron a la inversa- mediante la estructuración del discurso con los elementos compositivos, lingüísticos y temáticos de la oralidad, como creemos que quedó demostrado en el análisis de los apartados anteriores.

La propuesta transculturadora presente en la obra poética de Ramón Palomares considerada aquí, reclama, en primer lugar y a partir de los fenómenos de heterogeneidad cultural presentes en Venezuela y en América Latina en general, un cambio de códigos estéticos en la producción literaria desde las necesidades de la realidad latinoamericana y de igual manera formula implícitamente un proyecto de cambio social para aquellas comunidades cuyos modos de producción cultural difieren notablemente de los que caracterizan a los sectores metropolitanos de la dominación.

Sobre este aspecto debemos considerar nuevamente lo dicho en la primera parte del presente trabajo cuando nos referíamos - de acuerdo con Agustín Cueva- a que las prácticas literarias en cualquier período de la historia literaria se insertan en la matriz histórico-estructural donde se generan. La realidad cultural de un país o región es moldeada por la evolución de los fenómenos políticos y socio-económicos. En ese sentido, la obra de arte que se distingue por su proyección transculturadora es también - como lo señala García Canclini- un fenómeno de producción "porque consiste en una apropiación $\mathrm{y}$ transformación de la realidad material y cultural mediante un trabajo y para satisfacer una realidad social de acuerdo con el orden económico vigente en cada sociedad". ${ }^{30}$

Desde $E l$ reino, la poesía de Palomares refleja una creciente preocupación por transformar los códigos estéticos, adecuándolos a la realidad "material y cultural" de la Venezuela post-perezjimenizta. La evolución posterior de su obra señala de modo creciente este objetivo y, en efecto, Adiós Escuque logra instaurar una poética que totaliza los planteamientos iniciales de la misma manera que afirma el distanciamiento respecto a aquellos poetas que se acogieron al "mundo de la institucionalidad" que antes "combatían", ${ }^{31}$ desvinculándose - y hasta descreyendo- de las ideas que orientaban la producción literaria de la década del sesenta.

Contrariamente a esa postura, la poesía de Palomares, en cuanto que trabaja con elementos culturales del sector dominado y desde lo interior del mismo, ejerce una función desestabilizadora de los valores estatuidos por el orden cultural dominante para subvertirlos mediante una clara propuesta transculturadora que propicie transformaciones estéticas en el sistema literario vigente y sociales en beneficio del sector rural y campesino que ha

\footnotetext{
${ }^{30}$ Néstor García Canclini, Arte popular y sociedad en América Latina (México: Editorial Grijalbo, S.A., 1977) 55.

${ }^{31}$ Javier Lasarte Valcárcel, "Posible resplandor que apenas es. (La poesía de la promoción del 60 en esta década)", Imagen 100-23 (Caracas, octubre 1986) 20.
} 
servido de referente cultural, en esa vinculación de la obra literaria con la realidad material que la genera.

Sin embargo, con el cuestionamiento de los valores culturales institucionalizados no se están elaborando barreras para el diálogo intercultural. Por el contrario, el proyecto transculturador es un intento de comprensión distinto del fenómeno oral popular: un universo que, habiendo sido soslayado, se renueva y busca proyectarse como sistema cultural cuya existencia y legitimidad no puede ponerse en duda. 